\title{
Cross-infection of tumor cells by contact with $T$ lymphocytes loaded with Newcastle disease virus
}

\author{
CHRISTINA PFIRSCHKE and VOLKER SCHIRRMACHER \\ Division of Cellular Immunology, German Cancer Research Center (DKFZ), \\ Im Neuenheimer Feld 280, D-69120 Heidelberg, Germany
}

Received July 23, 2008; Accepted September 5, 2008

DOI: 10.3892/ijo_00000221

\begin{abstract}
Oncolytic virotherapy, a new type of cancer therapy involving viruses with oncolytic and immunostimulatory potential, is based on tumor selective viral replication, resulting in a specific lysis of tumor cells. Effective tumor targeting of oncolytic viruses remains a major problem because only a fraction of systemically applied viruses can reach the tumor tissue. We describe for the first time in an in vitro co-culture system that $\mathrm{T}$ lymphocytes can be loaded with Newcastle disease virus (NDV) in such a way that the virus load will be transferred to the tumor target cells upon contact of the T cells with tumor cells. The effectiveness of this NDV 'hitchhiking' on $T$ cells can be influenced by the amount of virus, the ratio of $\mathrm{T}$ cells to tumor cells, the activation status of the $\mathrm{T}$ cells and by the virulence of the virus as shown by flow cytometry, quantitative real-time PCR and fluorescence microscopy. In a tumor neutralization assay in vitro, monolayers of human tumor cells could be completely and effectively destroyed by the addition of polyclonally activated human $\mathrm{T}$ cells loaded with oncolytic NDV. This process involves the formation of large $\mathrm{T}$ cell clusters as revealed by phase-contrast microscopy. Loading of oncolytic NDV onto activated T cells and adoptive transfer into a tumor-bearing host might enhance the efficacy of adoptive $\mathrm{T}$ cell therapy of tumors as well as tumor targeting of oncolytic viruses.
\end{abstract}

\section{Introduction}

Nowadays much hope is directed towards a new type of cancer therapy involving viruses with oncolytic and immunostimulatory potential (1). Such oncolytic virotherapy is

Correspondence to: Professor Volker Schirrmacher, Division of Cellular Immunology, German Cancer Research Center, Im Neuenheimer Feld 280, D-69120 Heidelberg, Germany

E-mail: v.schirrmacher@dkfz.de

Key words: Newcastle disease virus, tumor vaccine, T cell immunity, hitchhiking based on the selective infection of tumor cells by certain naturally occurring or engineered lytic viruses, which leads to specific lysis of tumor cells a process termed oncolysis (2). As biological agents, viruses in contrast to cytostatic drugs have self-replicating potential and can thus enhance the anti-tumor effect once they have reached the tumor tissue (3). They might also kill cancer cells in a different way than cytostatic drugs and could thus break resistance to chemotherapy. For example, the death signals generated by oncolytic Newcastle disease virus (NDV) ultimately converge at the mitochondria (4) and lead to a p53-independent apoptotic cell death (5). Therefore this pathway should not be affected by mutations in $\mathrm{p} 53$ which can produce multidrug resistance in tumor cells (6). A major problem in the application of oncolytic viruses remains the proper tumor targeting. After systemic application such viruses might distribute in various normal tissues and only a fraction might reach the tumor tissue (7). Part of the virus might also become neutralized in the blood. A major break-through can be anticipated if virus transport through the blood to the tumor could be facilitated.

Viral hitchhiking on blood circulatory cells might be one way to overcome this problem. It has been shown for instance that $\mathrm{T}$ lymphocytes infected by retroviruses are able, within a certain time frame, to transport their virus load into the tumor (8-10). Similar observations were made with $\mathrm{T}$ cells loaded with vesicular stromatitis virus (11), an RNA virus that replicates in the cytoplasm. RNA viruses are rapidly emerging as particularly promising agents for virus therapy of cancer (3). Integral to the lifecycle of all RNA viruses is the formation of double stranded RNA which activates a spectrum of cellular defense mechanisms involving interferons (IFN) $\alpha$ and B. Mutations in tumor cells often cripple the interferon system allowing uninhibited proliferation and providing resistance to apoptosis. Therefore, tumors provide a relatively permissive substrate for the propagation of RNA viruses. The most promising ones are attenuated strains of mumps virus, measles virus, vesicular stomatitis virus, human reovirus, poliovirus, influenza virus and the Newcastle disease virus (12). The avian paramyxovirus NDV is an enveloped virus with a negative sense single stranded RNA genome of $\sim 15,000$ nucleotides. William A. Cassel and Joseph G. Sinkovics were the two main pioneers who in the 1960s and 1970s introduced NDV into the clinic as oncolytic agent and who developed NDV oncolysates as vaccines for immunotherapy $(13,14)$. In the last decade NDV has raised again 
considerable interest as an agent suitable for viral therapy of cancer (15), because of its safety, tumor-selective replication and its oncolytic and immune stimulatory properties $(16,17)$.

In the present study we investigated whether $\mathrm{T}$ lymphocytes might be capable of transporting and releasing NDV. We reported before that NDV can bind to T lymphocytes but does not replicate within them and will not produce new viral particles upon T cell infection (18). NDV binds to cells via its hemagglutinin-neuraminidase $(\mathrm{HN})$ protein which recognizes cell surface sialic acid containing receptors on glycoproteins or glycolipids of T cells and other cells $(19,20)$. Cell binding is normally followed by membrane fusion via the viral $F$ protein and thereby becomes an irreversible process. If some of the cell-bound virus is only loosely attached to the glycocalyx of the cells, it may be released upon contact with other cells. Such process would be important because it would allow NDV to hitchhike on blood circulating $\mathrm{T}$ cells. If such $\mathrm{T}$ cells were capable of transporting the virus into the tumor they should be able to release the virus upon contact with tumor cells thereby causing infection and oncolysis.

$\mathrm{T}$ cells, in particular tumor antigen-specific $\mathrm{T}$ cells are exploited for adoptive immunotherapy of cancer. Such cells would be perfect tumor targeting devices if they could transport oncolytic NDV with them. Through their tumor-antigen specific $\mathrm{T}$ cell receptor they have the capacity to distinguish tumor from normal cells and through their migratory capacity in tissues and their capacity of directed movement via chemotactic and haptotactic gradients they would be perfect cellular carriers for anti-tumor viruses.

The present study will demonstrate that human T lymphocytes, in particular activated peripheral blood derived T cells, are capable in vitro to transfer cell surface attached NDV to tumor cells upon co-culture. NDV transfer from $\mathrm{T}$ cells to tumor cells will be shown not to require the enzyme heparanase and thus differs from the process of transfer of retroviruses (8). Finally, we demonstrate that monolayers of human MCF-7 breast carcinoma cells can be effectively destroyed upon co-culture with polyclonally activated human $\mathrm{T}$ cells that were loaded with oncolytic NDV. T cells can thus be advocated for being used as carriers to transport NDV to sites of tumors.

\section{Materials and methods}

Animals. DBA/2 and Balb/c mice were obtained from Charles River WIGA (Sulzfeld, Germany). IFN $\alpha$ receptor-deficient $\left(\mathrm{IFN} \alpha \mathrm{R}^{-/-}\right.$) mice were kindly provided by Dr R. Zawatzky, German Cancer Research Center, Heidelberg, Germany. Animals were used at 6-12 weeks of age and kept under specific pathogen-free conditions.

Isolation and activation of murine T lymphocytes. Single cell suspensions were obtained from spleens and lymph nodes of Balb/c mice. Lysis of erythrocytes was performed with $155 \mathrm{mM} \mathrm{NH}_{4} \mathrm{Cl}, 10 \mathrm{mM} \mathrm{KHCO}$ and $0.1 \mathrm{mM}$ EDTA. Mouse $\mathrm{T}$ cells were purified using the Dynal mouse $\mathrm{T}$ cell Negative Isolation Kit from Invitrogen (Karlsruhe, Germany). The purity of $\mathrm{CD}^{+} \mathrm{T}$ cells in the isolated cell fraction determined by flow cytometry was $\sim 99 \%$. Murine T cells were cultured in RPMI-1640 medium (PAA Laboratories, Pasching,
Austria) supplemented with $10 \%$ fetal calf serum (FCS; Biochrom, Berlin, Germany), 10 nm HEPES, 100 U/ml penicillin, $100 \mu \mathrm{g} / \mathrm{ml}$ streptomycin (all provided by PAA), $50 \mu \mathrm{M}$ ß-mercaptoethanol (Sigma-Aldrich, Seelze, Germany) and $25 \mathrm{U} / \mathrm{ml}$ rIL-2 (Chiron Therapeutic, Emeryville, USA). Purified mouse $\mathrm{T}$ cells were activated for $20 \mathrm{~h}$ with Dynabeads mouse CD3/CD28 T cell expander from Invitrogen (bead-tocell ratio $=1: 1)$. The $\mathrm{T}$ cell activation status was analyzed by FACS staining for CD25 and CD69 expression.

Immunization of mice and harvesting of peritoneal exudate cells. Naive DBA/2 mice were primed by injection into the external ear pinna (i.e.) of a subtumorigenic dose of $5 \times 10^{4}$ viable ESb 289 lymphoma cells (21) in $50 \mu 1$ RPMI-1640 medium. To generate in situ activated peritoneal exudates cells (PEC), the primed mice were challenged 7 days later with $1 \times 10^{7}$ inactivated ESb 289 tumor cells intraperitoneally (i.p.). Inactivation of tumor cells was achieved by X-irradiation with 100 Gy from a ${ }^{137} \mathrm{Cs}$ source (Gammacell 1000, Atomic Energy of Canada Ltd., Ontario, Canada). In situ activated immune PECs were harvested 3 days after i.p. challenge by peritoneal lavage from the abdominal cavity. The characteristics of these cells (22) and their ability to transfer protective anti-tumor immunity $(23,24)$ have been described before.

Extraction of bone marrow derived macrophages from IFNaR ${ }^{-1-}$ mice. Murine macrophages were generated by growing bone marrow cells flushed from femora in RPMI-1640 medium supplemented with 10\% FCS, $10 \mathrm{~nm}$ HEPES, $100 \mathrm{U} / \mathrm{ml}$ penicillin, $100 \mu \mathrm{g} / \mathrm{ml}$ streptomycin and $20 \%$ murine macrophage colony-stimulating factor (M-CSF)-containing supernatant obtained from murine L929 fibroblasts. After 7 days the adherent cells were isolated and the macrophage phenotype was determined by FACS staining of F4/80. The purity of $\mathrm{F} 4 / 80^{+}$cells in the adherent cell fraction was $\sim 76 \%$.

Isolation and activation of human peripheral blood $T$ lymphocytes. Human peripheral blood T cells (PBTC) were isolated from buffy coat preparations of healthy donors obtained from the Blood Donation Center, University of Heidelberg. Peripheral blood mononuclear cells (PBMC) were isolated by Ficoll density gradient separation using Biocoll Separation Solution (Biochrom). PBTC were purified from PBMC using the Dynal $\mathrm{T}$ cell Negative Isolation Kit from Invitrogen according to the manufacturing procedures. $\mathrm{CD}^{+}$and $\mathrm{CD}^{+} \mathrm{T}$ cell subpopulations were directly extracted out of PBMC using the Dynal CD8 Positive Isolation Kit and Dynal CD4 Positive Isolation Kit, respectively (both from Invitrogen). PBTC were cultured in RPMI-1640 medium supplemented with 10\% human AB-Serum (Sigma-Aldrich), $10 \mathrm{~nm}$ HEPES, $100 \mathrm{U} / \mathrm{ml}$ penicillin, $100 \mu \mathrm{g} / \mathrm{ml}$ streptomycin, $100 \mathrm{U} / \mathrm{ml} \mathrm{rIL}-2$ and $1.2 \mathrm{U} / \mathrm{ml} \mathrm{rIL}-4$ (PromoCell, Heidelberg). The purity of $\mathrm{CD}^{+}, \mathrm{CD}^{+}$and $\mathrm{CD}^{+}$cells in the isolated cell fractions determined by FACS analysis were between 91-99\%. PBTC were activated for $20 \mathrm{~h}$ with anti-CD3 (clone Okt3)/ anti-CD28 (clone 9.3) antibodies ( $2 \mu \mathrm{g} / 4 \times 10^{6}$ respectively) or with Dynabeads CD3/CD28 T cell expander from Invitrogen (bead-to-cell ratio $=1.1$ ). The $\mathrm{T}$ cell activation status was analyzed using FACS staining for CD25 and CD69 expression. 
Cell lines. The human breast cancer cell line MCF-7 was provided by the American Type Culture Collection (ATCC, LGC Standards, Wesel, Germany, HTB-22). MCF-7 cells were cultured in DMEM (PAA) supplemented with $10 \%$ FCS and $10 \mathrm{nM}$ HEPES. A heparanase recombinant cell line, MCF-7-Hpa (25) provided by Professor I. Vlodavsky (Cancer and Vascular Biology Research Center, Haifa, Israel) was cultured in DMEM supplemented with $10 \%$ FCS, $10 \mathrm{nM}$ HEPES, $300 \mu \mathrm{g} / \mathrm{ml}$ Geneticin 418 (Invitrogen). The human hyperplastic non-tumorigenic breast epithelial cell line MCF-10 was also provided by ATCC (CRL-10317) and grown in DMEM supplemented with $5 \%$ horse-serum, $100 \mathrm{ng} / \mathrm{ml}$ choleratoxin, $10 \mu \mathrm{g} / \mathrm{ml}$ insulin, $500 \mathrm{ng} / \mathrm{ml}$ hydrocortisone, $20 \mathrm{ng} / \mathrm{ml}$ epidermal growth factor (EGF) (all provided by Sigma-Aldrich), $10 \mathrm{~nm}$ HEPES, $100 \mathrm{U} / \mathrm{ml}$ penicillin and $100 \mu \mathrm{g} / \mathrm{ml}$ streptomycin. The murine $\mathrm{T}$ cell lymphoma cell line ESb 289 (21) was cultured in RPMI-1640 supplemented with $10 \%$ FCS and $10 \mathrm{nM}$ HEPES. All cell lines were cultured at $37^{\circ} \mathrm{C}$ in a humidified atmosphere containing $5 \% \mathrm{CO}_{2}$.

Viruses. Two different avirulent, nonlytic NDV strains (NDVUlster, NDFL-EGFP) and two virulent, lytic NDV strains (MTH-68 and NDFLtagEGFP) were used $(26,27)$. All viruses were propagated in embryonated chicken eggs, harvested from the allantoic fluid, purified by ultracentrifugation as described (28) and cryopreserved in aliquots at $-80^{\circ} \mathrm{C}$. The virus was quantified by a hemagglutination assay. One hemagglutination unit (HU) is defined as the smallest virus concentration leading to visible sheep erythrocyte agglutination.

Virus binding and modification of cells with NDV. In the standard infection procedure cell suspensions were washed with FCS-free medium and $1 \times 10^{7}$ cells were incubated with $50 \mathrm{HU}$ of NDV in a final volume of $1 \mathrm{ml}$ of FCS-free medium for $1 \mathrm{~h}$ at $37^{\circ} \mathrm{C}$ in a humidified atmosphere containing $5 \%$ $\mathrm{CO}_{2}$. During the incubation, cells were shaken every $15 \mathrm{~min}$. The cells were then washed twice and further cultured in medium containing FCS or stained with antibodies and analyzed by flow cytometry. This procedure allowed to measure: i) only the bound virus (staining of viral $\mathrm{F}$ protein after $1 \mathrm{~h}$ of binding); or ii) viral replication after $20 \mathrm{~h}$ [staining of viral $F$ protein at the cell surface or analyzing the intracellular enhanced green fluorescent protein (EGFP) signal].

Co-culture of tumor cell lines with virus modified carrier cells. T cells $\left(\mathrm{CD}^{+}, \mathrm{CD}^{+}, \mathrm{CD}^{+}\right), \mathrm{PBMC}$, macrophages, PEC and MCF-7 tumor cells as carrier cells were modified with NDV as described in the standard procedure above, washed, stained for trypan blue exclusion and counted for content of viable cells. NDV modified carrier cells were then added to tumor target cells (MCF-7, MCF-7-Hpa, MCF-10) and co-cultured. The ratio of tumor target cells to NDV modified carrier cells varied from $1: 5$ to $1: 0.25$. The coculture was performed for 3, 6, 9, 20 and $30 \mathrm{~h}$. Directly infected tumor cell cultures were used for comparison. The extent of tumor cell infection by NDV either direct or indirect (cross-infected) was evaluated by flow cytometry.

Flow cytometry. For flow cytometry $2 \times 10^{5}-5 \times 10^{5}$ cells per sample were used for analysis with the FACSCalibur or
FACScan flow cytometer (Becton-Dickinson, Heidelberg). All antibodies were diluted in FACS buffer (phosphatebuffered saline containing 5\% FCS). Cells were washed with FACS buffer and blocked with FACS buffer containing 5\% endobulin (Baxter, Frankfurt, Germany) for $10 \mathrm{~min}$ on ice. Cells were washed with FACS buffer and then incubated with the primary antibody for $20 \mathrm{~min}$ on ice. Subsequently the cells were washed and incubated with fluorochrom-conjugated secondary antibodies (if primary antibodies were not directly fluorochrom coupled) for $20 \mathrm{~min}$ on ice, protected from light and after final washing steps analyzed on a flow cytometer. The following primary anti-bodies were used: mouse anti-F (clone Icii) (viral fusion protein of NDV), rat anti-mouse F4/80 (clone C1:A3-1; Cedarlane Laboratories Ltd., Burlington, Canada) and mouse anti-human EpCAM (clone HEA-125, kindly provided by Dr G. Moldenhauer, German Cancer Research Center). The mouse anti-human CD3-FITC (clone SK7), mouse anti-human CD4-PE (clone RPA-T4), mouse anti-human CD8-FITC (clone HIT8a), mouse anti-human CD25-FITC (clone M-A251) and mouse anti-human CD69$\mathrm{PE}$ (clone FN50), as well as armenian hamster anti-mouse CD3e-FITC (clone 145-2C11) and armentian hamster antimouse CD69-FITC (clone H1.2F3) were obtained from Becton-Dickinson. Furthermore rat anti-mouse CD25-PE (clone PC61.5.3 from EuroBioSciences, Friesoythe, Germany) and goat $\mathrm{F}\left(\mathrm{ab}^{\prime}\right)_{2}$ anti-mouse Ig-PE from Southern Biotech, Birmingham, USA were used. Dead cells were excluded from the analyzed cell population performing a propidium iodide staining at a final concentration of $1 \mu \mathrm{g} / \mathrm{ml}$ (Sigma-Aldrich). All FACS data were analyzed with CellQuest (BectonDickinson) or FlowJo software (Tree Star, San Carlos, USA).

CFSE staining. To differentiate MCF-7 target cells from MCF-7 cells modified with virus, MCF-7 target cells were first stained with carboxyfluorescein succinimidyl ester (CFSE). The CellTrace CFSE Cell Proliferation Kit (Invitrogen) was used according to manufacturing procedures. The final concentration of $10 \mu \mathrm{M}$ CFSE was used for staining.

Preparation of total RNA and synthesis of cDNA. For total RNA extraction from cells the RNeasy mini kit (Qiagen, Hilden, Germany) was used according to the manufacturer's instructions. Cells were disrupted using the Qia shredder columns from Qiagen. Total RNA (500 ng) was reversely transcribed into cDNA using Oligo- $(\mathrm{dT})_{12-18}$ primers and the SuperScript ${ }^{\mathrm{TM}}$ II Reverse Transcriptase (both from Invitrogen).

Analyses of viral M gene expression by quantitative real-time $P C R$. Real-time PCR for the viral M gene and for the housekeeping gene $B$-actin was performed using a GeneAmp 5700 Sequence Detection System (Applied Biosystems, Weiterstadt, Germany). After an initial incubation of $25 \mu 1$ reaction mixture (Eurogentec, Seraing, Belgium) for $10 \mathrm{~min}$ at $95^{\circ} \mathrm{C}$, amplification was performed for 40 cycles consisting of a $15-\mathrm{sec}$ hold at $95^{\circ} \mathrm{C}$ and a 1 -min hold at $60^{\circ} \mathrm{C}$. The expression of the target gene was normalized with the housekeeping gene after it had been ensured that the amplification efficiency was the same. For gene detection SYBR-Green I (Eurogentec) 
was used. The following primers were used for analysis: viral $M$ gene (sense 5'-agt gat gtg ctc gga cct tc-3', antisense 5'-cct gag gag agg cat ttg cta-3') and $\beta$-actin (sense $5^{\prime}$-agt act ccg tgt gga tcg gc-3', antisense 5'-gct gat cca cat ctg ctg ga-3').

Cytospin and NDV fluorescence microscopy. After $20 \mathrm{~h}$ coculture of adherent MCF-7 cells with PBTC, modified with $50 \mathrm{HU}$ NDV-Ulster the non-adherent cells were washed off and the MCF-7 cells were harvested with trypsin-EDTA (PAA). Single cell suspensions were dispersed onto slides using a Cytospin Cytocentrifuge (Shandon Cytospin 2, Thermo Fisher Scientific, Waltham, USA) at $500 \mathrm{rpm}$ for $3 \mathrm{~min}$ and fixed in methanol for $5 \mathrm{~min}$ and in acetone for $20 \mathrm{sec}$ at $-20^{\circ} \mathrm{C}$. The slides were blocked with $5 \%$ chicken serum (Santa Cruz Biotechnology, Heidelberg) for $15 \mathrm{~min}$ and after washing steps incubated with polyclonal anti-NDV rabbit serum or monoclonal mouse anti-human pan-cytokeratin antibody (Santa Cruz) for $1 \mathrm{~h}$ at room temperature. The secondary antibodies Alexa Fluor 594 chicken anti-rabbit Ig or Alexa Fluor 488 chicken anti-mouse Ig (Invitrogen) were applied for further $30 \mathrm{~min}$ at room temperature protected from light. DAPI (Serva, Heidelberg) was used for cell nucleus staining. Immunofluorescence microscopical images were recorded with an Axiophot II photomicroscope (Carl Zeiss, Jena, Germany).

Tumor neutralization assay. Details of the tumor neutralization assay (TNA) were described by Haas et al (29). MCF-7 cells were co-cultured with NDV modified PBTC for 2 days to analyze the anti-tumor effect after viral hitchhiking on PBTC or polyclonally activated PBTC. At the end, MTS [3-(4,5dimethylthiazol-2-yl)-5-(3-carboxy-methoxyphenyl)-2-(4sulfophenyl)-2H-tetrazolium] (Promega, Mannheim, Germany) was added to the MCF-7 cell layer. Viable cells can convert the yellow MTS-tetrazol component into the brown formazan product. The color alteration can be measured with an ELISA reader (Perkin-Elmer Wallac, Freiburg, Germany) at $490 \mathrm{~nm}$. The percent tumor growth inhibition (TGI) was calculated as described (29).

\section{Results}

Modification of peripheral blood derived T lymphocytes with $N D V$. To investigate what happens when normal or activated $\mathrm{T}$ lymphocytes from peripheral blood of healthy donors (PBTC) are infected by NDV we performed various assays to test: i) for viral antigens at the cell surface, ii) for cytoplasmic viral RNA (M gene), iii) for cytoplasmic viral protein (EGFP), and iv) for presence of infectious progeny virus in the supernatant of infected cells. The results are shown in Fig. 1. PBTC were incubated with increasing amounts [hemagglutination units (HU)] of the lentogenic strain NDV-Ulster or of the more virulent strain MTH-68 (Fig. 1A). After $1 \mathrm{~h}$, the cells were washed and one part of the NDV-modified PBTC was stained with a mouse monoclonal antibody against the viral $\mathrm{F}$ protein followed by goat anti-mouse Ig-PE. The second part of the PBTC was incubated for $20 \mathrm{~h}$ before FACS analysis was performed. A dose-dependent increase of viral antigens at the cell surface was detected. The percentage of cells carrying viral antigen was similar after the adsorption step for $1 \mathrm{~h}$ and after further incubation for $20 \mathrm{~h}$. Fig. 1B shows results from quantitative real-time PCR of viral M gene RNA in infected normal PBTC, in infected PBTC pre-activated by anti-CD3 and anti-CD28 beads (aPBTC) and in infected MCF-7 human breast carcinoma tumor cells. After $20 \mathrm{~h}$ of infection with recombinant lentogenic NDV (NDFL-EGFP) the aPBTC expressed the highest amount of viral $M$ gene while non-activated PBTC expressed much lower amounts. The tumor cells in comparison expressed intermediate amounts. In Fig. 1C, the cells depicted in Fig. 1B were tested for cytoplasmic expression of the fluorescent EGFP protein by flow cytometry. While $>60 \%$ of the three infected cell types expressed the virally transferred gene, the mean fluorescent intensity of the cells was quite different. Tumor cells and aPBTC showed a very high mean fluorescent intensity compared to the non-activated PBTC. We tested supernatants of the three infected cell types for the presence of infectious progeny virus (Fig. 1D). While supernatants of infected tumor cells contained infectious virus particles, supernatants of non-activated and activated PBTC did not contain infectious virus particles.

Transfer of NDV from T lymphocytes to tumor target cells. Our first aim was to test whether NDV modified T cells could transfer NDV to tumor target cells upon in vitro coincubation. Such viral transfer which will be termed 'hitchhiking' was tested with purified T cells, with total peripheral blood derived mononuclear cells (PBMC) and with PBMC from which we had removed the T cells (non-PBTC fraction). The cells were modified with 50 HU NDFL-EGFP, washed and then co-cultured for $20 \mathrm{~h}$ with human MCF-7 cells. Afterwards we performed FACS analysis for EGFP-positive cells and gated on the tumor cells which were clearly distinct from the $\mathrm{T}$ cell population. As shown in Fig. 2A $25 \%$ of tumor cells were infected and EGFP-positive after coincubation with NDV modified PBTC. After co-incubation with PBMC or non-PBTC only $\sim 12 \%$ of tumor cells were virus infected. Upon direct infection of tumor cells by equal amounts of virus we detected $75 \%$ EGFP-positive cells. These results demonstrate that NDV which has attached to normal cells such as PBMC or purified T lymphocytes can be transferred to tumor target cells. The data also suggest that $\mathrm{T}$ cells may be particularly well suited for hitchhiking of NDV.

Since direct infection of tumor cells and infection via hitchhiking from normal cells may take a different time course, we next performed kinetics experiments. Fig. 2B shows the time course of infection of MCF-7 tumor cells by NDV via hitchhiking on PBTC. This is compared with the kinetics of direct infection of MCF-7 cells. By mean fluorescent intensity of the EGFP signal it can be seen that infection via the direct route takes about $10 \mathrm{~h}$ while infection via hitchhiking on $\mathrm{T}$ cells lasts $\sim 20 \mathrm{~h}$.

In Fig. $1 B$ and $C$ we showed that activated $T$ cells can be better infected than non-activated $\mathrm{T}$ cells. We observed that aPBTC expressed much more viral mRNA and EGFP protein but they did not produce infectious progeny virus. When testing the hitchhiking capacity of aPBTC we found that they were more active than non-activated PBTC as shown by the results in Fig. 2C. 
A

Modification of PBTC with NDV:

cell surface

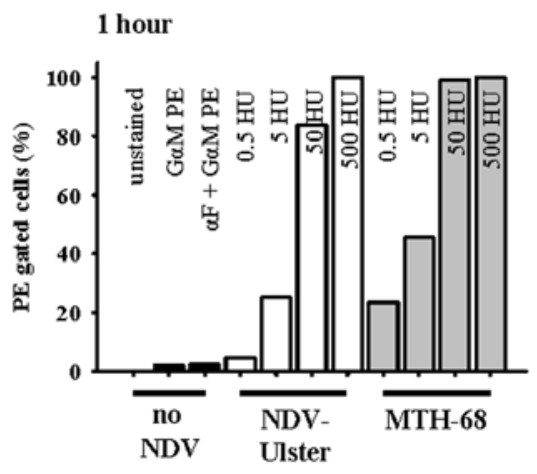

B

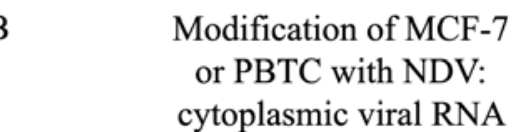

$\mathrm{C}$

Modification of MCF-7 or PBTC with NDV: cytoplasmatic EGFP

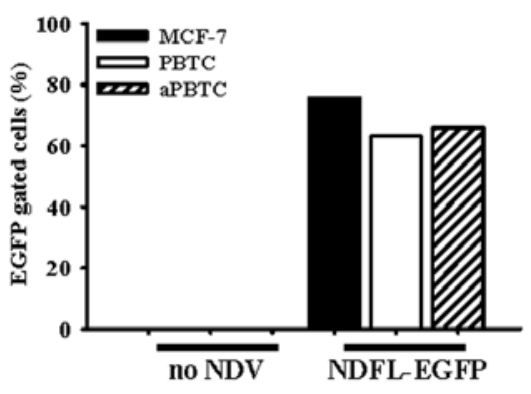

20 hours

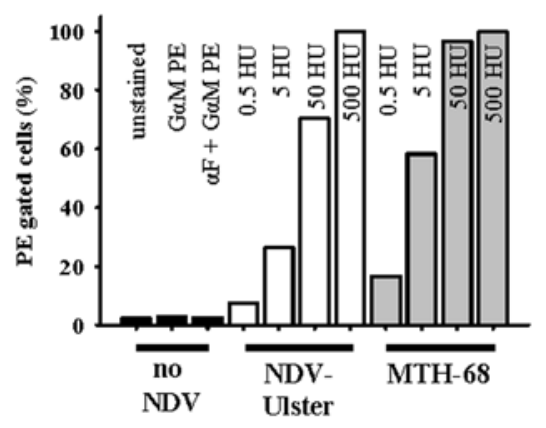

$\mathrm{D}$

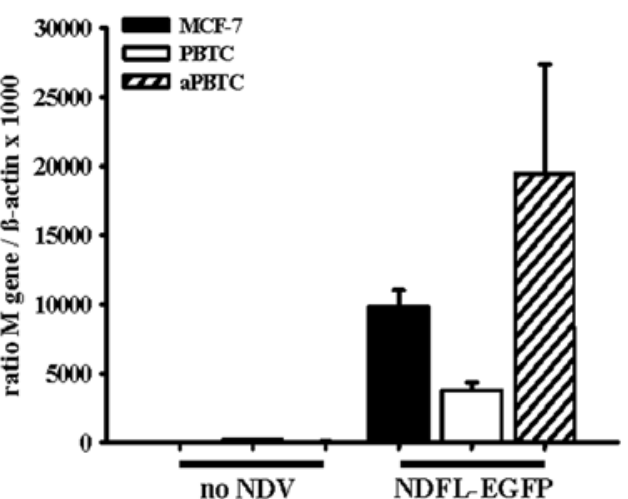

Infectious progeny virus in supernatant

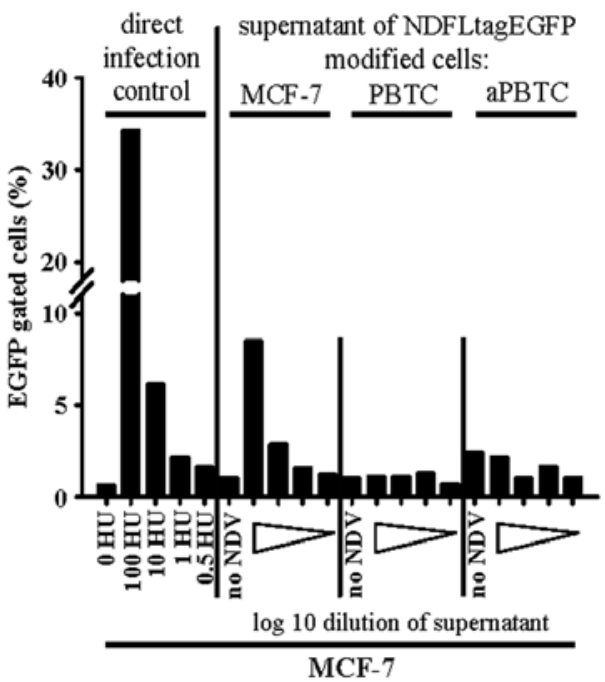

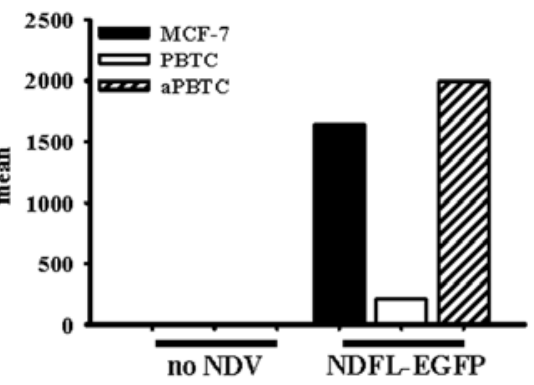

Figure 1. Human peripheral blood derived T lymphocytes can be modified with NDV but NDV is not able to replicate in T lymphocytes. (A) The binding of NDV to human peripheral blood derived T cells (PBTC) was analyzed 1 and $20 \mathrm{~h}$ after treatment with NDV by staining the T cells for surface expression of the viral fusion $(\mathrm{F})$ protein [murine anti-F antibody $(\alpha \mathrm{F})$ followed by goat anti-mouse Ig-PE (GaM PE)] using flow cytometry. Percent of PE positive cells is displayed. Different amounts of NDV-Ulster or MTH-68 were added to T cells. (B) Real-time PCR analysis for viral M gene expression with mRNA isolated from non-activated PBTC (PBTC), CD3/CD28 activated PBTC (aPBTC) and MCF-7 tumor cells without (no NDV) or with modification by NDV (50 HU NDFL-EGFP) for 20 h. (C) Analysis by flow cytometry for cytoplasmatic viral EGFP signal from PBTC, aPBTC and MCF-7 cells without or with modification by NDV (50 HU NDFL-EGFP) for $20 \mathrm{~h}$. Percent of EGFP positive cells as well as the mean of the EGFP positivity are shown. Representative data from one of two experiments are shown (A-C). (D) Analysis of the formation of infectious progeny virus by PBTC, aPBTC or MCF-7 tumor cells. Cells were modified with $10 \mathrm{HU}$ of NDFLtagEGFP for 2 days. This virus has multicyclic replication competence so that progeny virus particles are infectious. The supernatants of these cells were transferred to untreated MCF-7 tumor cells, $20 \mathrm{~h}$ later the tumor cells were analyzed for EGFP expression via flow cytometry. The supernatants were tested in log 10 dilutions. MCF-7 control samples without supernatants of NDV modified cells (no NDV) as well as direct infection controls of MCF-7 tumor cells were analyzed.

We furthermore investigated whether certain subsets of $\mathrm{T}$ cells might be better suited than others in the hitchhiking phenomenon. The results from a hitchhiking experiment performed with total $\mathrm{CD}^{+} \mathrm{T}$ cells and purified $\mathrm{CD}^{+}$or $\mathrm{CD}^{+} \mathrm{T}$ cells (Fig. 2D) revealed that both $\mathrm{T}$ cell subsets are similarly active in this phenomenon.

Qualitative and quantitative aspects of NDV hitchhiking. To visualize tumor cell infection by NDV via hitchhiking on $\mathrm{T}$ cells we performed a hitchhiking experiment as before with NDV-Ulster on PBTC co-cultured with MCF-7 cells for $20 \mathrm{~h}$.
After washing off non-adherent cells, the remaining cells were cyto-centrifuged and stained with DAPI to see the nuclei, with antibodies to cytokeratin to visualize the tumor cells and with antibodies to NDV to analyze the viral antigens. Arrows in Fig. 3A and B show tumor cells which are infected by NDV. Fig. 3A shows the tumor cells after direct infection and Fig. 3B after infection via hitchhiking on PBTC.

After the observation that supernatants of infected $\mathrm{T}$ cells did not contain infectious virus particles and that infected $\mathrm{T}$ cells could transfer infectious virus to tumor cells we following tested the dependency of this hitchhiking 
A

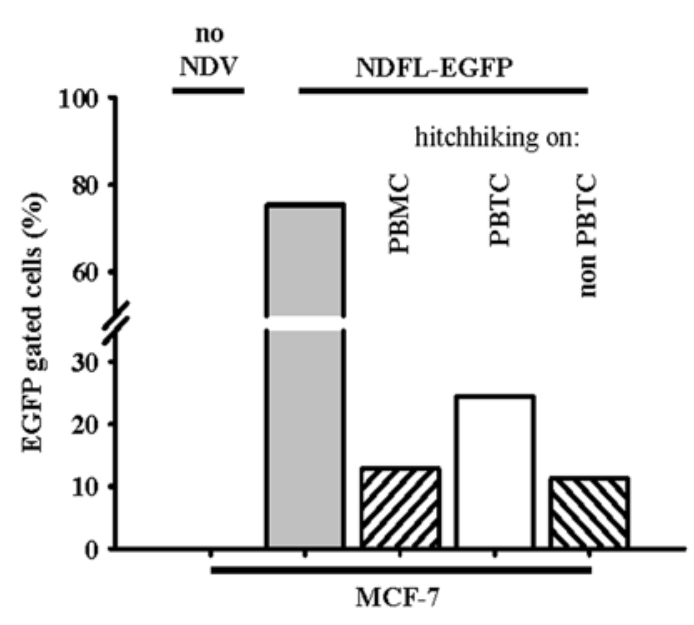

$\mathrm{C}$

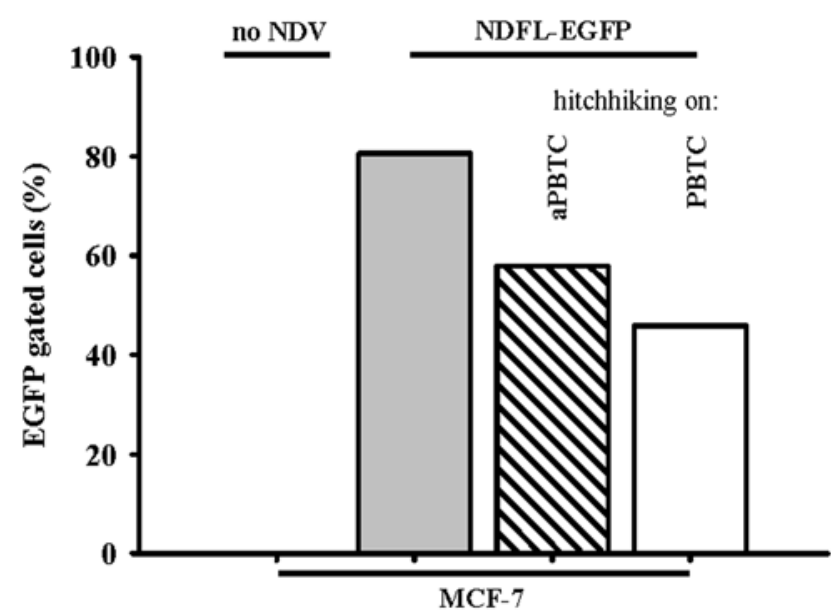

B

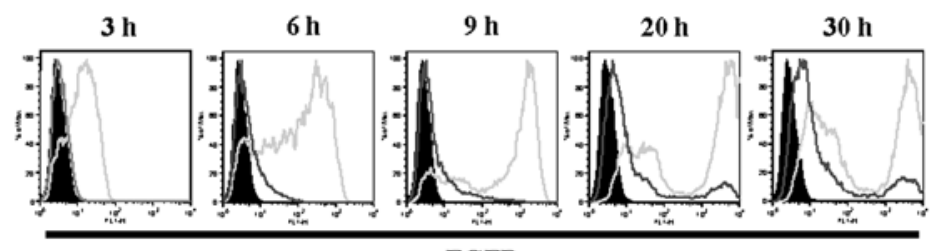

EGFP

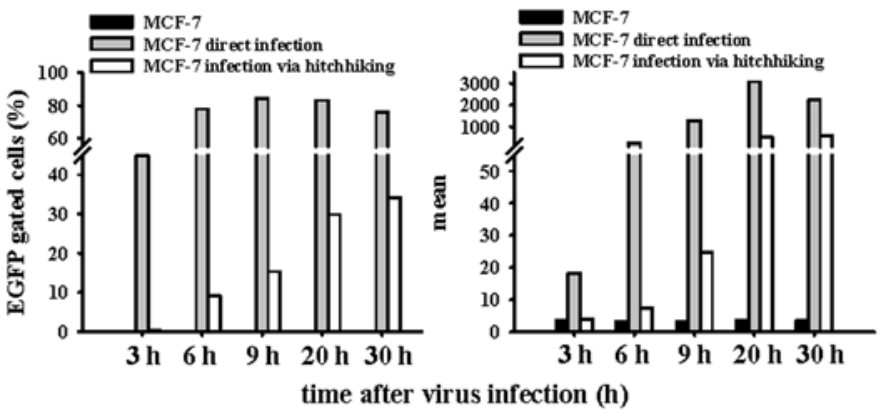

D

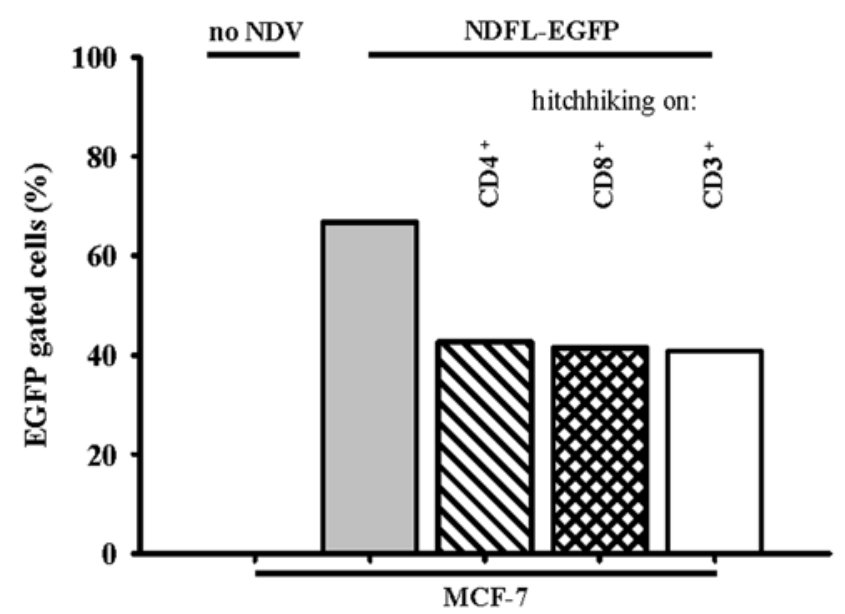

Figure 2. NDV can be transferred from T lymphocytes via a hitchhiking process to tumor target cells. (A) Peripheral blood derived mononuclear cells (PBMC), PBTC and non-PBTC (T cell depleted fraction after PBTC isolation) were modified with NDV (50 HU NDFL-EGFP) and afterwards co-cultured with untreated MCF-7 tumor cells for $20 \mathrm{~h}$ (tumor cell to T cell ratio; 1:4). MCF-7 cells with or without modification by NDV were used as controls. The EGFP signal was analyzed by flow cytometry after $20 \mathrm{~h}$ of co-culture. (B) The time-course of the hitchhiking process of NDV (50 HU NDFL-EGFP) on PBTC was analyzed after 3, 6, 9, 20 and $30 \mathrm{~h}$ of co-culture with MCF-7 cells (tumor cell to T cell ratio; 1:5) by flow cytometry. Percent of EGFP positive cells as well as the mean of the EGFP positivity are shown. (C) Analysis of hitchhiking of NDV (50 HU NDFL-EGFP) on non-activated PBTC (PBTC) and on CD3/CD28 activated PBTC (aPBTC) co-cultured with MCF-7 cells using a tumor cell to T cell ratio of 1:2. The EGFP signal was analyzed by flow cytometry after $20 \mathrm{~h}$ of co-culture. (D) Analysis of hitchhiking of NDV (50 HU NDFL-EGFP) on CD3 ${ }^{+}, \mathrm{CD}^{+}{ }^{+}$and CD8 ${ }^{+} \mathrm{PBTC}$ co-cultured with MCF-7 cells using a tumor cell to $\mathrm{T}$ cell ratio of 1:5. The EGFP signal was analyzed by flow cytometry after $20 \mathrm{~h}$ of co-culture. Representative data from one of two experiments are shown (A-C). MCF-7 cells with and without modification by NDV were used as controls (A-D).

phenomenon on the MCF-7 to $\mathrm{T}$ cell ratio. The results from Fig. 3C show that using a 1:1 ratio the phenomenon can be clearly seen. The best results, however, are observed at an 1:5 ratio. Fig. 3D shows that there is also a dependency of hitchhiking efficiency using different amounts of NDV on PBTC. Interestingly there was more hitchhiking observed from T cells loaded with $500 \mathrm{HU}$ than with T cells loaded only with $50 \mathrm{HU}$, a dose used in all previous experiments.

Test for influence of tumor-associated heparanase. Since it has been shown in another virus to tumor cell hitchhiking model that tumor associated heparanase (Hpa) was required for virus release (8), we decided to find out whether this is true also for NDV hitchhiking. We chose a spontaneously immortalized human breast-epithelial cell line, MCF-10, which is Hpa-negative and compared it with the human breast carcinoma cell line MCF-7, which is low in Hpa expression, and with MCF-7 cells transfected with Hpa. Hitchhiking experiments were performed with these three cell lines coincubated with PBTC as described before. However, the highest percentage of target cells infected via hitchhiking was seen with MCF-10 cells and the lowest with MCF-7-Hpa 
A
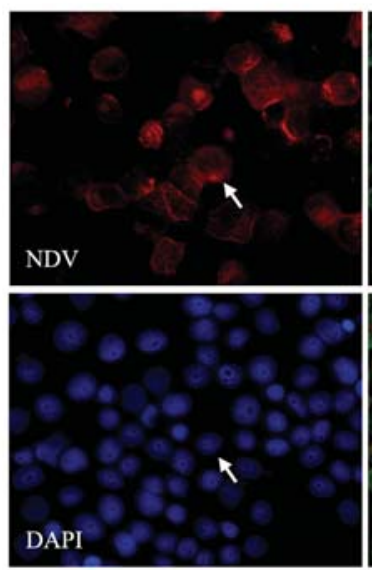

$\mathrm{C}$ Hitchhiking on PBTC: dependency on MCF-7 / PBTC ratio

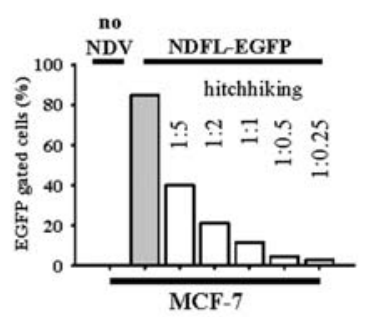

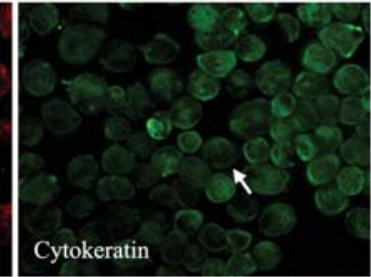

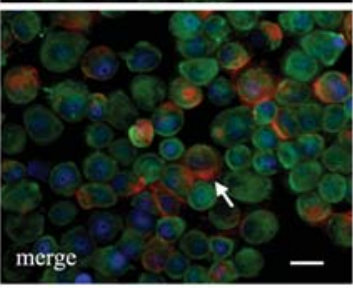

B

infection of MCF-7 via hitchhiking
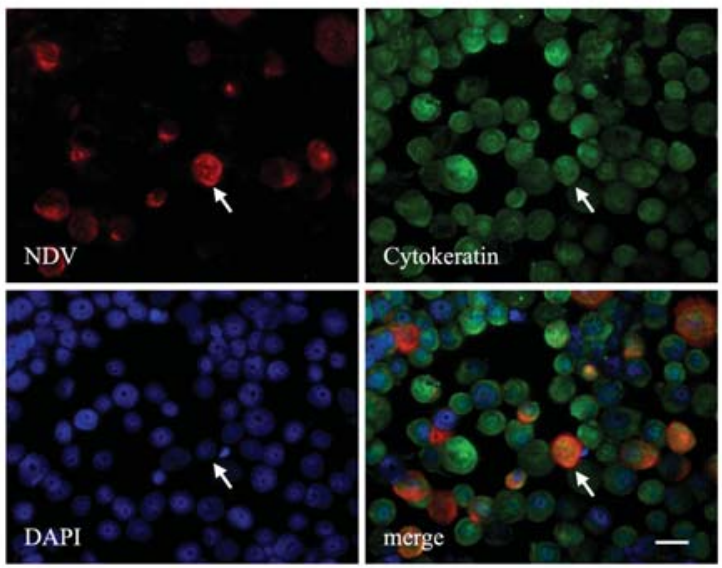

$\mathrm{D}$

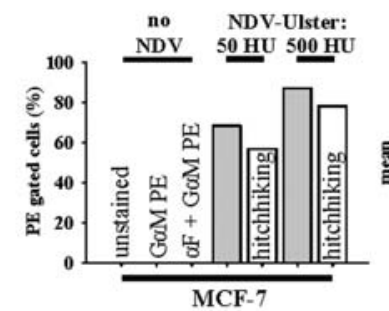

Hitchhiking on PBTC: dependency on amount of NDV

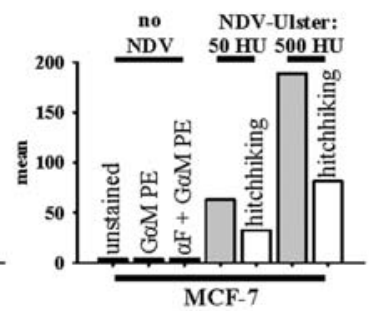

Figure 3. The efficiency of transfer of NDV from T lymphocytes to tumor target cells depends on the co-culture ratio and the virus dose used. Hitchhiking of NDV (50 HU NDV-Ulster) on PBTC, co-cultured with MCF-7 cells using a tumor cell to T cell ratio of 1:5. After $20 \mathrm{~h}$ (A) the directly infected MCF-7 cells and (B) the co-cultured MCF-7 cells were analyzed for virus expression by fluorescence microscopy. The MCF-7 cells were dispersed onto slides using a cytospin centrifuge. Cytokeratin staining was used to visualize the tumor cells (green), NDV staining to visualize the virus (red) and DAPI staining in blue for the cell nuclei. Merge pictures show NDV positive tumor cells (white arrows). Bar, $20 \mu \mathrm{m}$. (C) Hitchhiking of NDV (50 HU NDFL-EGFP) on PBTC co-cultured with MCF-7 cells. Different tumor cell to T cells ratios $(1: 0.25,1: 0.5,1: 1,1: 2,1: 5)$ were analyzed. The EGFP signal was measured by flow cytometry after $20 \mathrm{~h}$ of co-culture. Percent of EGFP positive cells as well as the mean of the EGFP positivity are displayed. (D) Hitchhiking of NDV on PBTC co-cultured with MCF-7 cells using a tumor cell to T cell ratio of 1:2. Analysis of different NDV doses (50 and 500 HU NDV-Ulster). The NDV positive cells ( $\alpha$ F staining) were analyzed by flow cytometry after $20 \mathrm{~h}$ of co-culture. MCF-7 cells without NDV (no NDV) or with modification by NDV were used as controls (C and D). Representative data from one of two experiments are indicated (C and D).

cells (Fig. 4). These results strongly suggest that Hpa is not necessary for hitchhiking of NDV from $\mathrm{T}$ cells to tumor target cells.

Hitchhiking of NDV on murine T lymphocytes, macrophages and peritoneal exudate cells. All hitchhiking experiments so far have been performed with human cells. In order to be able to perform viral hitchhiking experiments in vivo in mice, we tested the capacity of murine T cells and also macrophages for transferring the virus to tumor target cells (Fig. 5). It can be seen from Fig. 5A that activated $\mathrm{T}$ (aT) cells were more active than resting $\mathrm{T}$ cells. NDV infected murine bone-marrow derived macrophages from interferon $\alpha$ receptor knock-out mice (Fig. 5B) also had hitchhiking capacity. In these cells NDV was able to replicate because type I interferons could not repress viral replication (Fournier and Schirrmacher, unpublished data).

We previously demonstrated that peritoneal exudate cells (PEC) from anti-tumor immunized mice (iPEC) could transfer protective anti-tumor-immunity into $\mathrm{T}$ cell deficient nude mice (23). Such iPEC cells contain mainly macrophages and
Hitchhiking on PBTC: test for influence of tumor-associated heparanase

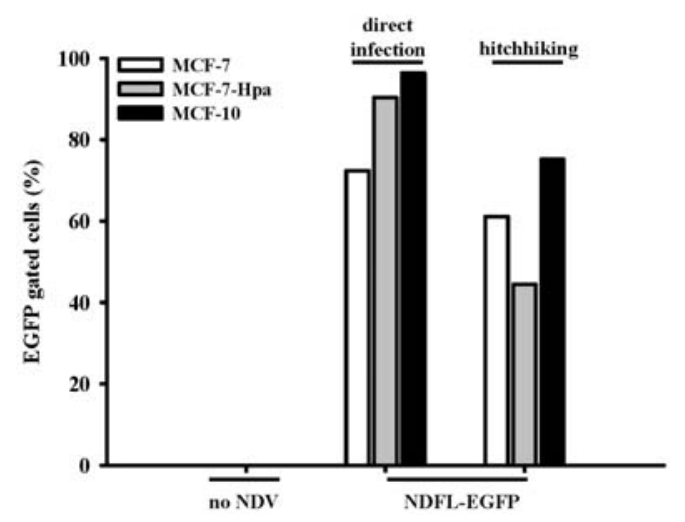

Figure 4. The transfer of NDV from T lymphocytes to tumor target cells is independent of tumor-associated heparanase. Analysis of EGFP expression by MCF-7, MCF-7-Hpa and MCF-10 cells co-cultured with NDV (50 HU NDFL-EGFP) modified PBTC for $20 \mathrm{~h}$ at a tumor cell to T cell ratio of 1:4. MCF-7, MCF-7-Hpa and MCF-10 cells with or without modification by NDV were analyzed as controls. Data for the percentage of EGFP positive cells from one of two experiments are shown. 
A Hitchhiking on murine T cells
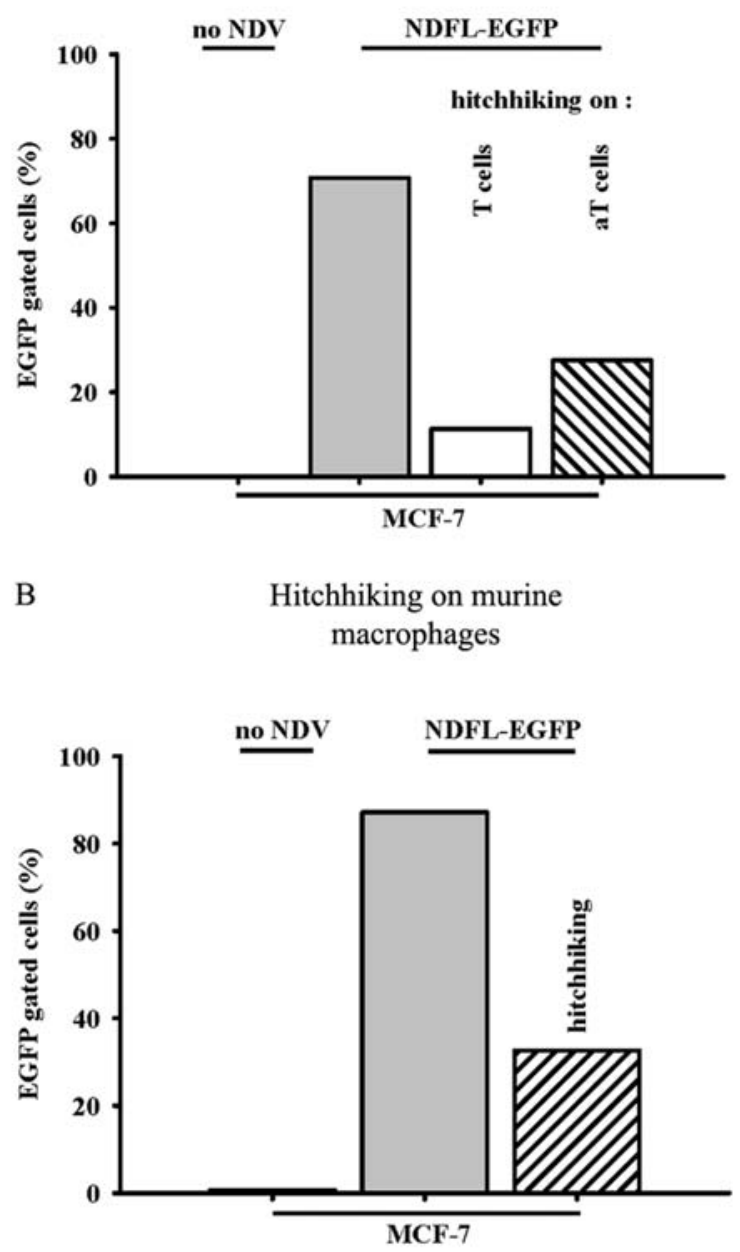

C Hitchhiking on murine PEC

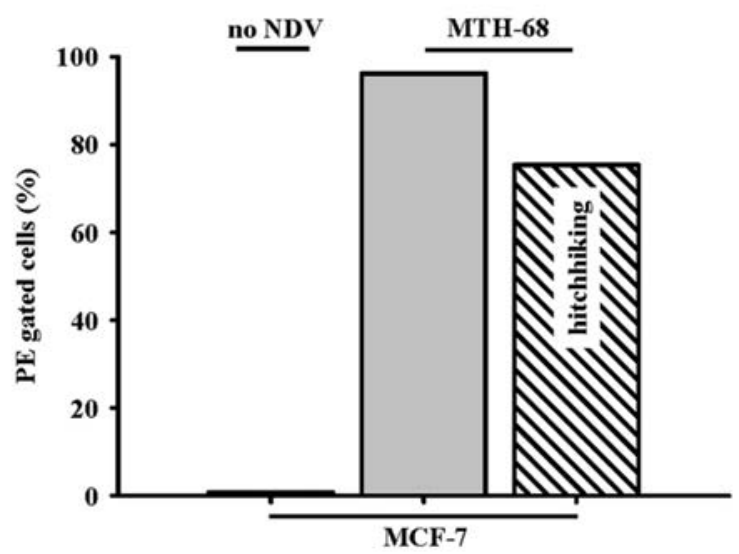

Figure 5. NDV can be transferred from murine T lymphocytes, macrophages and peritoneal exudate cells to tumor target cells. (A) Co-culture of NDV (50 HU NDFL-EGFP) modified murine non-activated $\mathrm{T}$ cells ( $\mathrm{T}$ cells) as well as CD3/CD28 activated T cells (aT cells) with MCF-7 cells for $20 \mathrm{~h}$ at a tumor cell to $\mathrm{T}$ cell ratio of 1:2. The percentage of EGFP positive cells are shown. (B) Co-culture of NDV (50 HU NDFL-EGFP) modified murine macrophages with EpCAM positive MCF-7 tumor cells for $20 \mathrm{~h}$ at a tumor cell to macrophage ratio of 1:2. (C) Co-culture of NDV (50 HU MTH-68) modified murine peritoneal exudates cells (PEC) with MCF-7 cells for $20 \mathrm{~h}$ at a tumor cell to PEC ratio of 1:5. The NDV positive cells ( $\alpha \mathrm{F}$ staining) from $\mathrm{PE}$ gated cells are displayed in \%. Representative data from one of two experiments is presented. MCF-7 cells with or without modification by NDV were used as controls (A-C).
Hitchhiking on tumor cells: lentogenic versus mesogenic NDV

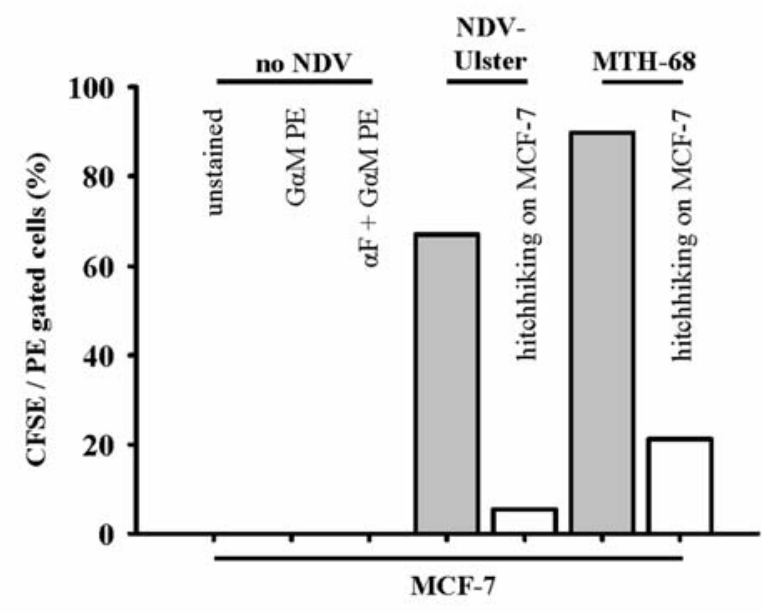

Figure 6. Low capacity of tumor cells to transfer NDV via hitchhiking to other tumor target cells. Co-cultures of NDV (50 HU NDV-Ulster, $50 \mathrm{HU}$ MTH-68) modified MCF-7 cells with virus-untreated CFSE stained MCF-7 cells for $20 \mathrm{~h}$, at a target cell to tumor cell ratio of 1:5 are shown. Cell surface expressed viral $\mathrm{F}$ protein (murine anti-F antibody $(\alpha \mathrm{F})$ was analyzed by flow cytometry. CFSE/PE double positive gated cells are displayed in $\%$. MCF-7 cells with and without modification by NDV were used as controls. Representative data are indicated from one of two experiments.

$\mathrm{T}$ cells (22). Among the latter are tumor antigen-specific memory $\mathrm{T}$ cells which are responsible for the transfer of long-term protective immunity (24). Since such cells are ideal candidates for tumor targeting experiments in vivo we tested their hitchhiking capacity in vitro. Representative results are shown in Fig. 5C. Approximately 75\% of MCF-7 tumor cells could become virus-infected after contact with MTH-68 loaded iPEC. This is the highest value of hitchhiking capacity we have observed so far.

NDV hitchhiking on tumor cells. We also tested under similar conditions as before the capacity of tumor cells for transferring NDV to other untreated tumor target cells. The experiment was performed with either the lentogenic strain NDV-Ulster which has a monocyclic replication cycle or with the mesogenic NDV strain MTH-68 which has a multicyclic replication cycle. MCF-7 tumor cells were first modified with either of the two viruses, then washed and co-incubated with CFSE-labeled non-infected MCF-7 tumor target cells. As with the virus-carrying $\mathrm{T}$ cells before, we used a ratio of five virus-carrying tumor cells to one non-infected tumor target cell. FACS-analysis of CFSE gated cells revealed after $20 \mathrm{~h}$ only $\sim 5 \%$ infected cells in case of lentogenic virus and $\sim 20 \%$ in case of mesogenic NDV (Fig. 6). These values are conspicuously low in comparison to what has been observed with $\mathrm{T}$ lymphocytes, in particular with activated $\mathrm{T}$ cells.

Anti-tumor activity of $T$ cells loaded with NDV. We also tested the anti-tumor activity of NDV released from PBTC or from pre-activated $\mathrm{T}$ cells (aPBTC) in vitro (Fig. 7). For this we employed the tumor neutralization assay (TNA) previously described by Haas et al (29), in which tumor monolayers are co-cultured with the $\mathrm{T}$ cells for several days. 
A

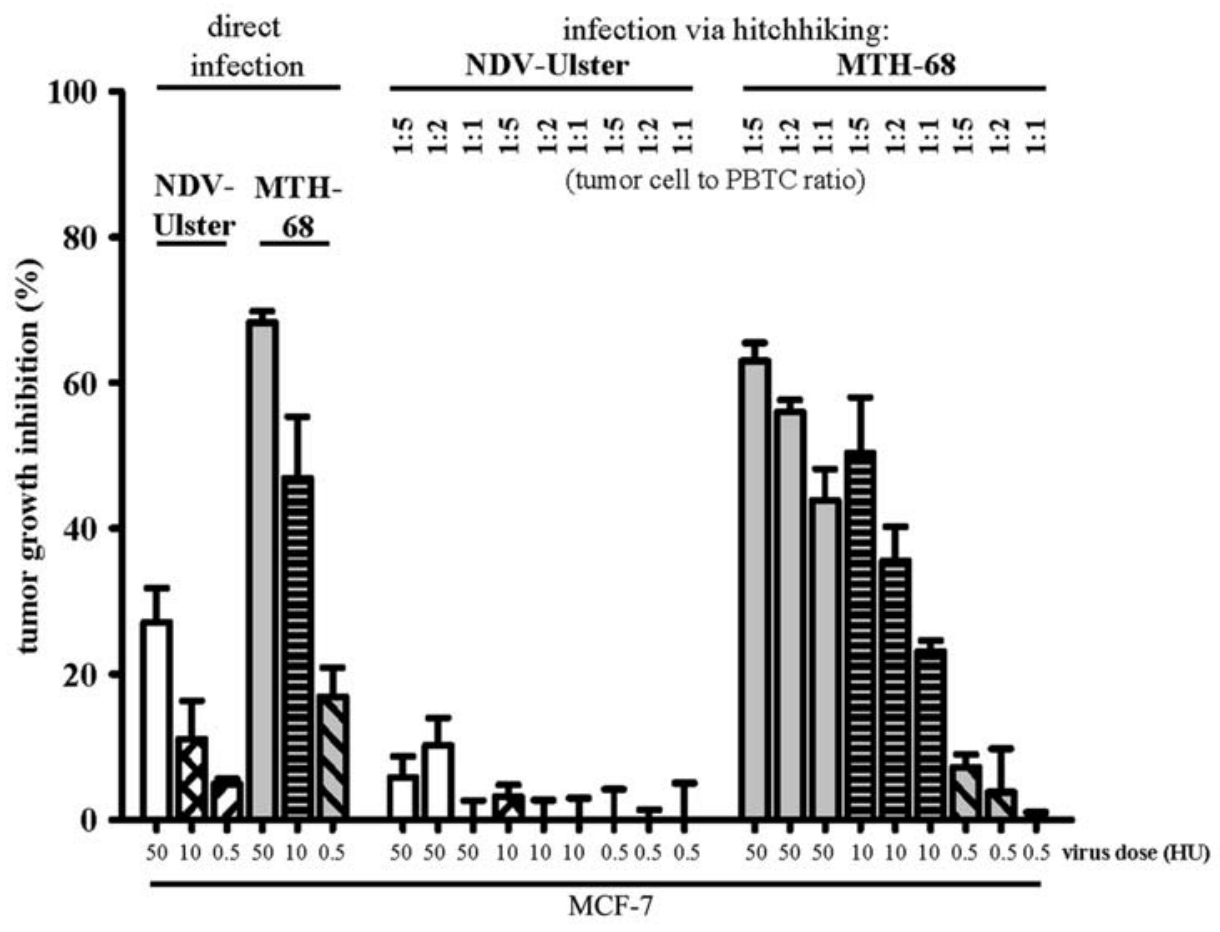

B

NDV on PBTC

infection via hitchhiking:

NDV on aPBTC

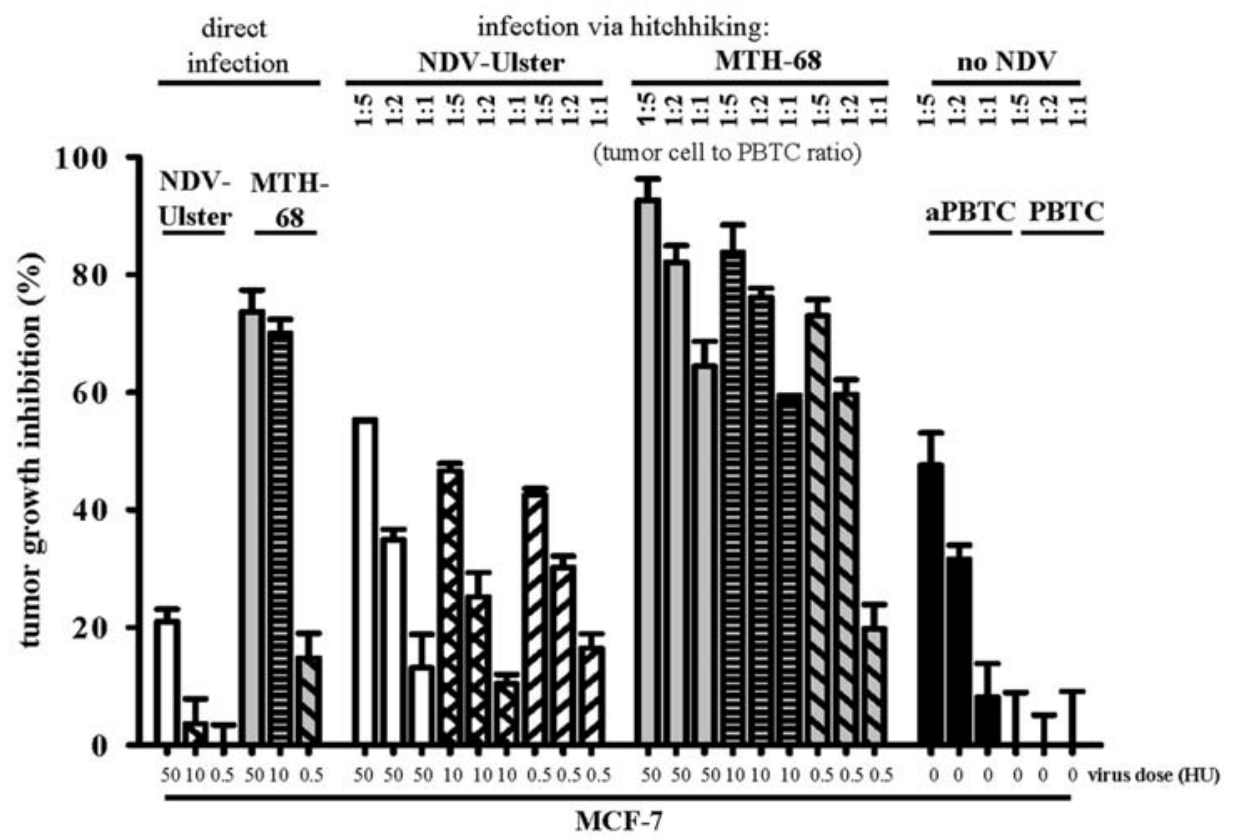

Figure 7. Tumor growth in vitro is inhibited by NDV transferred via T cells. The inhibition of tumor cell growth was determined after co-culture of MCF-7 cells with NDV (NDV-Ulster or MTH-68) modified: (A) non-activated PBTC (PBTC) or (B) CD3/CD28-activated PBTC (aPBTC) for 2 days in a tumor neutralization assay. Different tumor cell to T cell ratios $(1: 1,1: 2,1: 5)$ as well as different NDV doses $(0.5 \mathrm{HU}, 10 \mathrm{HU}, 50 \mathrm{HU})$ were tested. MCF-7 cells with modification by NDV (direct infection) as well as MCF-7 cells co-cultured with PBTC or aPBTC without NDV were used as controls. Representative data are shown from one of two experiments.

The anti-tumor effect is then measured by uptake of MTS by the remaining live tumor cells. Fig. 7A shows the percent tumor growth inhibition (TGI) by MTH-68 virus released from non-activated PBTC. 50\% TGI was observed at a T cell to tumor cell ratio of 5:1 when the T cells were loaded with $10 \mathrm{HU}$ of the virus. A similar effect was seen when $10 \mathrm{HU}$
MTH-68 was directly added to the tumor cells. As to be expected, the less virulent NDV strain Ulster showed less anti-tumor activity, both after direct infection or after hitchhiking. Interestingly much stronger anti-tumor activity was observed when we used CD3/CD28 activated PBTC (Fig. 7B). Again 50\% TGI was observed with these cells without virus 
A

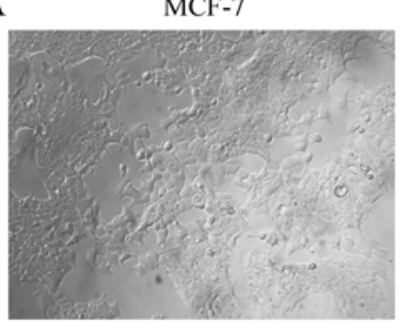

B

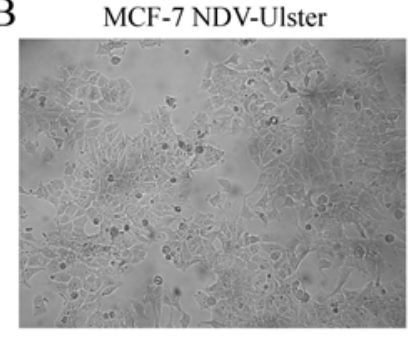

$\mathrm{C}$

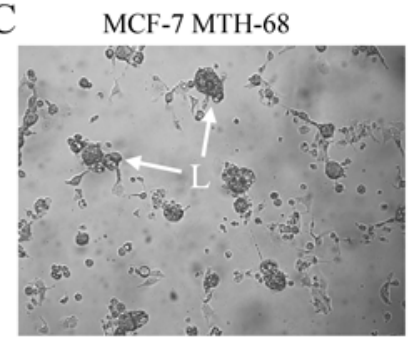

MCF-7 + aPBTC

NDV-Ulster (1:5)

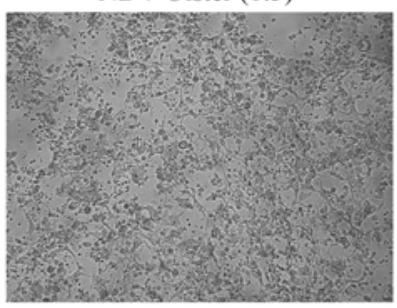

MCF-7 + aPBTC

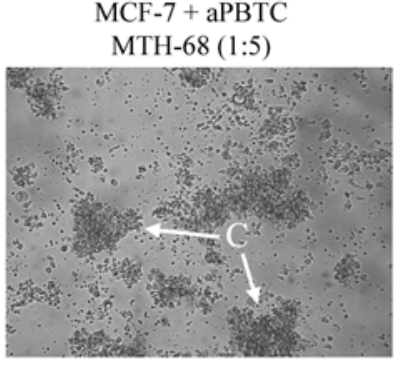

MCF-7 + aPBTC (1:5)

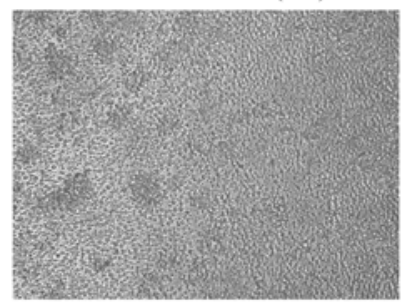

$\mathrm{MCF}-7+\mathrm{aPBTC}$

NDV-Ulster (1:2)

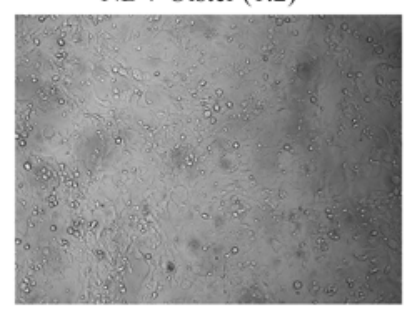

$\mathrm{MCF}-7+$ aPBTC MTH-68 (1:2)

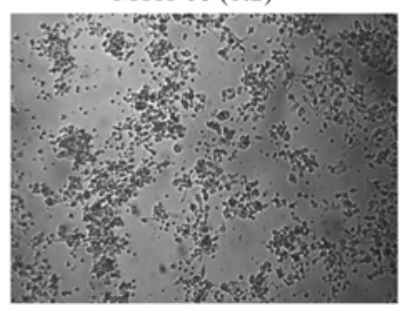

$\mathrm{MCF}-7+$ aPBTC

NDV-Ulster (1:1)

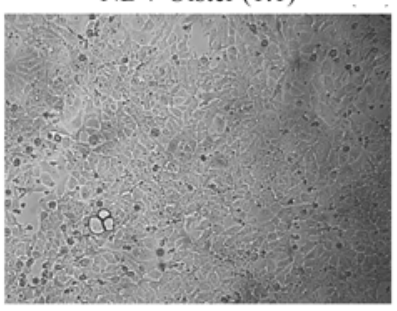

$\mathrm{MCF}-7+$ aPBTC MTH-68 (1:1)

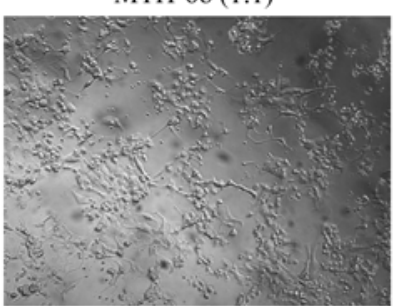

Figure 8. Images using phase-contrast microscopy of tumor growth inhibition in the TNA in vitro. MCF-7 cells were co-cultured: (A) without; (B) with NDVUlster or (C) MTH-68 modified CD3/CD28 activated T cells (aPBTC) for 2 days. Different tumor cell to T cell ratios were tested (1:1, 1:2, 1:5). Magnification, $\mathrm{x} 4$; L, lysed tumor cells; C, clusters of T cells.

when being used as above at a ratio of 5:1. Only slightly higher anti-tumor effects were observed with aPBTC loaded with NDV-Ulster while much stronger activity was seen with aPBTC loaded with MTH-68. With this combination the TGI was even higher than investigated after direct infection of MCF-7 tumor cells.

In Fig. 8 phase-contrast microscopical images of the above TNA are shown. MCF-7 tumor cells untreated with NDV in single culture or in co-culture with polyclonally activated PBTC showed unaffected tumor cell morphology (Fig. 8A). Fig. 8B shows the effect of treatment of MCF-7 cells with NDV-Ulster either directly or via hitchhiking on PBTC while Fig. 8C shows the effect of treatment with the oncolytic strain MTH-68. As can be clearly seen, the oncolytic strain exerted much stronger morphological changes on the tumor cell monolayer, either when applied directly or via hitchhiking. This on the one hand is visible by the tumor cell lysis (depicted by L) following direct infection of MCF-7 cells and on the other hand by the formation of cell clusters (indicated by C) when using MTH-68 loaded aPBTC for hitchhiking.

\section{Discussion}

Biotherapeutics such as viruses and immune cells offer new possibilities for cancer therapy. A variety of viral-based and immune cell-based therapies have demonstrated efficiency in preclinical models $(30,31)$. Efficiency was also demonstrated recently in a randomized controlled clinical study with a virusmodified autologous tumor cell vaccine in colon carcinoma (32). As single agents viruses may, however, not be sufficiently effective in cancer patients. One way that may allow these agents to fulfill their undoubted potential would be to combine them. Viruses with inherent oncolytic properties can be used as new therapeutic agents $(3,33)$. They can also be used as vectors for cancer gene therapy $(34,35)$. The proper targeting of tumor tissue by viruses is, however, still a major problem. When applied to a tumor-bearing host, a viral vector may have to transit trough several distinct vascular beds and tissues to encounter the desired tumor target. Tumor targeting of NDV could be improved by employing bispecific adapter proteins (36). Another approach is to use particular cells as virus carriers. T lymphocytes - when surface loaded with viruses may facilitate tumor targeting. T cells patrol the body, can penetrate deep into multilayered tissues and can even cross the blood-brain barrier provided they receive the appropriate homing signals. Once a tumor specific $\mathrm{T}$ cell encounters the tumor cell expressing its specific target antigen, effector functions are triggered which in turn will recruit and activate additional $\mathrm{T}$ cells. If such $\mathrm{T}$ cells, upon encounter of tumor cells, release viruses these can infect the tumor cells. Such infection may result in increased release of tumor antigens, immunostimulatory cytokines, danger signals and cofactors. If the virus is replication competent it may amplify the oncolytic 
effect in the tumor tissue or it may amplify a therapeutic gene if used as a gene therapy vector.

This report describes for the first time that $\mathrm{T}$ lymphocytes, of human or murine origin can be loaded with NDV. When such virus-loaded $\mathrm{T}$ cells are co-cultured with tumor cells much of the virus load is transferred to the tumor cells causing their infection and destruction. The effectiveness of this NDV hitchhiking on $\mathrm{T}$ cells depends on a variety of parameters which are documented: i) the amount of virus given to the $\mathrm{T}$ cells, ii) the ratio of $\mathrm{T}$ cells to tumor cells, iii) the activation status of the $\mathrm{T}$ cells and iv) the virulence of the virus. In a tumor neutralization assay in vitro, monolayers of human tumor cells could be completely destroyed by the addition of polyclonally activated human $\mathrm{T}$ cells loaded with oncolytic NDV. Under the microscope many large cell clusters were seen when the tumor cells were co-cultured with virus loaded activated T cells. When using non-activated T cells for NDV hitchhiking, cell clusters were also seen. However, these clusters were smaller and fewer. This observation suggests that activated $\mathrm{T}$ cells make better contacts with tumor cells and such contacts facilitate transfer of the virus. When tumor cells were loaded with virus and tested for their hitchhiking capacity much less virus was transferred than in the case of activated $\mathrm{T}$ cells. This corroborates our above interpretation and suggests that tumor cells are less active than activated $\mathrm{T}$ cells in mediating cell-cell contacts. Nevertheless, irradiated tumor cells have been used successfully as carriers for cell-mediated delivery of oncolytic parvoviruses for targeting metastases (37).

We also tested other cell carriers to deliver NDV to tumor cells. Macrophages were good cell carriers for NDV hitchhiking. The macrophages were taken from IFN $\alpha \mathrm{R}$ receptordeficient mice so that the cells could not respond to NDV induced IFN $\alpha$ and were thus susceptible to NDV infection. Also activated PEC from anti-tumor immunized mice which consist mostly of macrophages and T cells (22) were very potent to transfer NDV to tumor cells. Such immune PEC were derived from DBA/2 mice which had been primed with live ESb tumor cells in the ear pinna and which had been challenged one week later i.p. with an ESb tumor vaccine. This prime/challenge protocol leads to a powerful secondary anti-tumor $\mathrm{T}$ cell response characterized by a more than 8 fold enrichment of specific CD8 T cells and the release of various cytokines, including IL-12 and TNF- $\alpha$ (22). We performed some pilot in vivo experiments of NDV hitchhiking with iPEC cells. The cells were loaded with either oncolytic MTH-68 virus or with recombinant NDV producing GM-CSF (34) or IL-2 (35). Some ESb tumor-bearing mice treated with NDV loaded iPEC were seen which survived much longer than mice treated with iPEC without virus (Schirrmacher, unpublished data). Similar observations of anti-tumor activity were made with NDV loaded antiCD3/anti-CD28 polyclonally activated murine $\mathrm{T}$ cells, upon locoregional application for treatment of liver metastases of luciferase transfected CT26 colon carcinoma cells in Balb/c mice (Pfirschke and Schirrmacher, unpublished data). We previously reported from this model on the host mediated anti-tumor effects of oncolytic NDV (27).

Regarding the mechanism of transfer of NDV from activated $\mathrm{T}$ cells to tumor cells relatively little is known. We suggest that much of the cell bound virus is only loosely attached to the glycocalyx and can therefore be easily transferred to tumor cells when the $\mathrm{T}$ cells make contacts with the tumor cells. In case of hitchhiking of retroviral vectors on $\mathrm{T}$ cells, it has been shown that retroviral vector transduction requires expression of a receptor for the viral envelope but that virus-cell binding also occurs by a receptorindependent process (38). In this latter process the virus remains on the cell surface but is shielded from immune recognition by heparansulfate-glycosaminoglycans. In the retrovirus system, viral transfer to tumor cells was dependent on the enzyme heparanase which releases the shielding and which could either come from the tumor cells or from the activated T cells (8). This study revealed that transfer of NDV from T cells to tumor cells is independent of heparanase. The mechanism of transfer thus differs from that of retroviruses.

When studying the kinetics of the hitchhiking process it turned out that there was a delay in comparison to direct infection by about 6-12 h. The kinetics appeared faster than the previously reported transfer of retrovirus (8) or of vaccinia virus (33). For retroviruses viral hand off from $\mathrm{T}$ cells occurred within the first $24 \mathrm{~h}$ and decreased after $72 \mathrm{~h}$ (8). Vaccinia virus was released only after 48-72 h (39).

We also tested whether NDV hitchhiking on T cells would involve newly synthesized virion particles. While we observed an amplification of viral M-gene expression in activated T cells compared to non-activated $\mathrm{T}$ cells we could not detect in supernatants from activated $\mathrm{T}$ cells infectious virus particles. The increased activity of activated in comparison to nonactivated $\mathrm{T}$ cells with regard to viral hitchhiking and anti-tumor effects may be explained as follows: many of the activated $\mathrm{T}$ cells not only make cell contacts with the tumor cells but also have anti-tumor cytotoxic activity. This can be seen also from the TNA results of Fig. 7B. Our studies revealed that this anti-tumor activity of polyclonally activated $\mathrm{T}$ cells involves TRAIL (40) and cytokines such as interferon $\gamma$ (Schirrmacher, unpublished data). We could imagine that when virus-loaded activated $\mathrm{T}$ cells make contacts with tumor cells that NDV becomes focused in the contact zone. This would facilitate its release to the tumor cells. Lipid microdomains may play a role in the contact zone both for mediating the lethal hit from the activated $\mathrm{T}$ cell as well as for releasing the virus. The ordered assembly and release of infections NDV particles has been shown to depend on membrane lipid rafts (41).

\section{Acknowledgements}

We are grateful to Annette Arnold and Andreas Griesbach for excellent technical assistance, to Dr Ben Peeters for recombinant NDV, and to Dr Philippe Fournier and Dr Philipp Beckhove for their interest and for critical discussions of the experimental data.

\section{References}

1. Li QX, Liu G and Wong-Staal F: Oncolytic virotherapy as a personalized cancer vaccine. Int J Cancer 123: 493-499, 2008.

2. Liu TC, Thorne SH and Kirn DH: Oncolytic adenoviruses for cancer gene therapy. Methods Mol Biol 434: 243-258, 2008.

3. Russell SJ: RNA viruses as virotherapy agents. Cancer Gene Ther 9: 961-966, 2002. 
4. Elankumaran S, Rockemann D and Samal SK: Newcastle disease virus exerts oncolysis by both intrinsic and extrinsic caspase-dependent pathways of cell death. J Virol 80: 7522-7534, 2006.

5. Fabian Z, Csatary CM, Szeberenyi J and Csatary LK: p53independent endoplasmic reticulum stress-mediated cytotoxicity of a Newcastle disease virus strain in tumor cell lines. J Virol 81: 2817-2830, 2007.

6. Johnstone RW, Ruefli AA and Lowe SW: Apoptosis: a link between cancer genetics and chemotherapy. Cell 108: 153-164, 2002.

7. Bian H, Fournier P, Peeters B and Schirrmacher V: Tumortargeted gene transfer in vivo via recombinant Newcastle disease virus modified by a bispecific fusion protein. Int J Oncol 27: 377-384, 2005

8. Cole C, Qiao J, Kottke T, et al: Tumor-targeted, systemic delivery of therapeutic viral vectors using hitchhiking on antigen-specific T cells. Nat Med 11: 1073-1081, 2005.

9. Qiao J, Kottke T, Willmon C, et al: Purging metastases in lymphoid organs using a combination of antigen-non-specific adoptive $\mathrm{T}$ cell therapy, oncolytic virotherapy and immunotherapy. Nat Med 14: 37-44, 2008.

10. Rooney CM: Hitchhiker's guide to the T cell. Nat Med 11: 1051-1052, 2005.

11. Qiao J, Wang H, Kottke T, et al: Loading of oncolytic vesicular stomatitis virus onto antigen-specific $\mathrm{T}$ cells enhances the efficacy of adoptive T-cell therapy of tumors. Gene Ther 15: 604-616, 2008.

12. Schirrmacher V and Fournier P: Newcastle Disease Virus: a promising vector for viral therapy of cancer. In: Viral Therapy of Cancer. Harrington K, Pandha H and Vile R (eds.) John Wiley \& Sons Ltd., pp171-186, 2008.

13. Cassel WA and Garrett RE: Newcastle Disease Virus as an antineoplastic agent. Cancer 18: 863-868, 1965.

14. Sinkovics JG and Horvath JC: Newcastle disease virus (NDV): brief history of its oncolytic strains. J Clin Virol 16: 1-15, 2000 .

15. Nelson NJ: Scientific interest in Newcastle disease virus is reviving. J Natl Cancer Inst 91: 1708-1710, 1999.

16. Pecora AL, Rizvi N, Cohen GI, et al: Phase I trial of intravenous administration of PV701, an oncolytic virus, in patients with advanced solid cancers. J Clin Oncol 20: 2251-2266, 2002.

17. Schirrmacher V: Clinical trials of antitumor vaccination with an autologous tumor cell vaccine modified by virus infection: improvement of patient survival based on improved antitumor immune memory. Cancer Immunol Immunother 54: 587-598, 2005.

18. Schirrmacher V, Haas C, Bonifer R and Ertel C: Virus potentiation of tumor vaccine T-cell stimulatory capacity requires cell surface binding but not infection. Clin Cancer Res 3: 1135-1148, 1997.

19. Ferreira L, Villar E and Munoz-Barroso I: Gangliosides and $\mathrm{N}$-glycoproteins function as Newcastle disease virus receptors. Int J Biochem Cell Biol 36: 2344-2356, 2004.

20. Zeng J, Fournier P and Schirrmacher V: Induction of interferonalpha and tumor necrosis factor-related apoptosis-inducing ligand in human blood mononuclear cells by hemagglutininneuraminidase but not $\mathrm{F}$ protein of Newcastle disease virus. Virology 297: 19-30, 2002.

21. Schirrmacher V, Fogel M, Russmann E, Bosslet K, Altevogt P and Beck L: Antigenic variation in cancer metastasis: immune escape versus immune control. Cancer Metastasis Rev 1: 241-274, 1982.

22. Mahnke YD and Schirrmacher V: Characteristics of a potent tumor vaccine-induced secondary anti-tumor $\mathrm{T}$ cell response. Int J Oncol 24: 1427-1434, 2004.

23. Mahnke YD and Schirrmacher V: A novel tumour model system for the study of long-term protective immunity and immune $\mathrm{T}$ cell memory. Cell Immunol 221: 89-99, 2003.
24. Mahnke YD, Schwendemann J, Beckhove P and Schirrmacher V: Maintenance of long-term tumour-specific T-cell memory by residual dormant tumour cells. Immunology 115: 325-336, 2005.

25. Sommerfeldt N, Beckhove P, Ge Y, et al: Heparanase: a new metastasis-associated antigen recognized in breast cancer patients by spontaneously induced memory $\mathrm{T}$ lymphocytes. Cancer Res 66: 7716-7723, 2006.

26. Bian H, Fournier P, Moormann R, Peeters B and Schirrmacher V: Selective gene transfer in vitro to tumor cells via recombinant Newcastle disease virus. Cancer Gene Ther 12: 295-303, 2005.

27. Apostolidis L, Schirrmacher V and Fournier P: Host mediated anti-tumor effect of oncolytic Newcastle disease virus after locoregional application. Int J Oncol 31: 1009-1019, 2007.

28. Schirrmacher V, Haas C, Bonifer R, Ahlert T, Gerhards R and Ertel C: Human tumor cell modification by virus infection: an efficient and safe way to produce cancer vaccine with pleiotropic immune stimulatory properties when using Newcastle disease virus. Gene Ther 6: 63-73, 1999.

29. Haas C, Lulei M, Fournier P, Arnold A and Schirrmacher V: A tumor vaccine containing anti-CD3 and anti-CD28 bispecific antibodies triggers strong and durable antitumor activity in human lymphocytes. Int J Cancer 118: 658-667, 2006.

30. Thorne SH and Contag $\mathrm{CH}$ : Combining immune cell and viral therapy for the treatment of cancer. Cell Mol Life Sci 64: 1449-1451, 2007.

31. Schirrmacher V: T cell-mediated immunotherapy of metastases: state of the art in 2005. Expert Opin Biol Ther 5: 1051-1068, 2005.

32. Schulze T, Kemmner W, Weitz J, Wernecke KD, Schirrmacher V and Schlag PM: Efficiency of adjuvant active specific immunization with Newcastle disease virus modified tumor cells in colorectal cancer patients following resection of liver metastases: results of a prospective randomized trial. Cancer Immunol Immunother (In press)

33. Thorne SH, Hwang TH and Kirn DH: Vaccinia virus and oncolytic virotherapy of cancer. Curr Opin Mol Ther 7: 359-365, 2005.

34. Janke M, Peeters B, De Leeuw O, et al: Recombinant Newcastle disease virus (NDV) with inserted gene coding for GM-CSF as a new vector for cancer immunogene therapy. Gene Ther 14: 1639-1649, 2007.

35. Zhao H, Janke M, Fournier P and Schirrmacher V: Recombinant Newcastle disease virus expressing human interleukin-2 serves as a potential candidate for tumor therapy. Virus Res 136: 75-80, 2008.

36. Bian H, Wilden H, Fournier P, Peeters B and Schirrmacher V: In vivo efficacy of systemic tumor targeting of a viral RNA vector with oncolytic properties using a bispecific adapter protein. Int J Oncol 29: 1359-1369, 2006.

37. Raykov Z, Balboni G, Aprahamian M and Rommelaere J: Carrier cell-mediated delivery of oncolytic parvoviruses for targeting metastases. Int J Cancer 109: 742-749, 2004.

38. Pizzato M, Blair ED, Fling M, et al: Evidence for nonspecific adsorption of targeted retrovirus vector particles to cells. Gene Ther 8: 1088-1096, 2001.

39. Thorne SH, Negrin RS and Contag CH: Synergistic antitumor effects of immune cell-viral biotherapy. Science 311: 1780-1784, 2006.

40. Washburn B, Weigand MA, Grosse-Wilde A, et al: TNF-related apoptosis-inducing ligand mediates tumoricidal activity of human monocytes stimulated by Newcastle disease virus. J Immunol 170: 1814-1821, 2003.

41. Laliberte JP, McGinnes LW, Peeples ME and Morrison TG: Integrity of membrane lipid rafts is necessary for the ordered assembly and release of infectious Newcastle disease virus particles. J Virol 80: 10652-10662, 2006. 